\title{
Adubação Orgânica e Mineral na Cultura do Milho
}

\author{
André L. S. Pereira, Adilson Pelá, Gláucia M. Pelá, Rogério N. \\ Gonçalves, Rodrigo T. Mendes, Odilon P. M. Júnior
}

Com o objetivo de avaliar a adubação orgânica e mineral na cultura do milho, foram estudadas cinco doses de cama de aviário $\left(0 ; 2,5 ; 5 ; 10\right.$ e $\left.20 \mathrm{t} \mathrm{ha}^{-1}\right)$, e cinco doses de adubo mineral NPK $\left(100 ; 200 ; 300 ; 400\right.$ e $\left.500 \mathrm{~kg} \mathrm{ha}^{-1}\right)$, na formulação $05-$ 25-15, no delineamento em blocos casualizados, em esquema fatorial $5 \times 5$, com três repetições. Verificaram-se interações significativas entre adubação com cama de aviário e a adubação mineral para todas as variáveis estudadas. Conclui-se, de maneira geral, que o melhor resultado foi com 15 toneladas por hectare de cama de aviário, associada com $300 \mathrm{~kg} \mathrm{ha}^{-1}$ de adubo mineral NPK.

Palavras-chave: Zea mays L.; sustentabilidade; cama de aviário.

This study aimed to evaluate the organic and mineral fertilization in maize. We tested five doses of manure $\left(0,2.5,5,10\right.$ and $\left.20 \mathrm{tha}^{-1}\right)$ and five doses of mineral fertilizer NPK $\left(100,200,300,400\right.$ and $\left.500 \mathrm{~kg} \mathrm{ha}^{-1}\right)$ in the formulation $05-25-15$, in a randomized block design using a $5 \times 5$ factorial arrangement with three replications. There were significant interactions between fertilization with poultry manure and mineral fertilizer for all variables studied. We conclude, in general, the best result was with 15 tons per hectare of manure associated with $300 \mathrm{~kg} \mathrm{ha}^{-1}$ of mineral fertilizer NPK.

Keywords: Zea mays L sustainability; poultry litter. 


\section{Introdução}

Abusca pelo desenvolvimento sustentável consiste num dos maiores desafios para a humanidade e, em especial, para o Brasil ${ }^{1}$. O uso racional e o manejo dos recursos naturais, principalmente do solo, da água e da biodiversidade visam promover a agricultura sustentável; aumentar a oferta de alimentos, trabalho e renda no meio rural. Aumentar a produtividade das culturas agrícolas é uma necessidade tanto para atender à demanda por alimentos quanto para otimizar a utilização do recurso solo. A adubação tem papel fundamental no aumento da produtividade das culturas, mas sua utilização deve ocorrer de forma eficiente, evitando desperdícios e a contaminação ambiental.

Entre os cereais cultivados no Brasil, o milho é o mais expressivo em termos de produtividade. De acordo com suas características fisiológicas, a cultura tem alto potencial produtivo. No entanto, a produtividade média nacional, está em torno de $4,4 \mathrm{t} \mathrm{ha}^{-1}$, sendo considerada, ainda, muito baixa ${ }^{2}$, demonstrando que os diferentes sistemas de produção de milho deverão ser ainda bastante aprimorados para se obter aumento na produtividade e na rentabilidade dos produtores ${ }^{3}$.

Das tecnologias disponíveis no meio agrícola, a adubação tem sido considerada a mais limitante para o aumento da produtividade das lavouras de milho ${ }^{4}$. A não utilização de adubação mineral, de forma, satisfatória nessa cultura tem sido atribuída, em primeira instância, ao elevado custo dos fertilizantes. Portanto, isso tem forçado os produtores a buscar formas de cultivo que apresentem menores custos de produção, que causem menos danos possíveis ao meio ambiente, principalmente ao solo, objetivando um manejo conservacionista, com redução na dependência dos fertilizantes ${ }^{5,6,7,8}$. Entretanto, somente com a utilização de adubo químico, não é possível manter a produtividade em níveis satisfatórios, por um longo prazo'.

Com a acelerada degradação dos solos sob cultivo intensivo e da utilização de áreas com baixa fertilidade, têm sido preconizadas várias alternativas para a elevação da produtividade da cultura do milho, tais como a incorporação de resíduos culturais; a adubação verde; o uso de compostos orgânicos e os resíduos de animais ${ }^{10}$. Por sua vez, a grande exigência de nitrogênio torna a cultura do milho altamente responsiva à adubação nitrogenada ${ }^{11}$. Em solos de boa fertilidade ou devidamente corrigidos, é o nitrogênio que controla os níveis de produtividade do milho ${ }^{12}$. Dentre as fontes de nitrogênio que se encontram disponíveis para utilização, tem-se a adubação orgânica e a adubação mineral ${ }^{13}$.

Com a existência de uma considerável quantidade de resíduos orgânicos de origem animal, principalmente de bovinos e aves, disponíveis atualmente, prontamente disponíveis para o uso imediato como composto orgânico, provenientes de um grandes número de confinamentos e granjas distribuídos pelas diferentes regiões de produção agrícola, a adubação orgânica, ou mesmo a associação desta com a adubação mineral, tem-se constituído em alternativas economicamente viáveis para a maioria dos produtores $^{10}$.

Nos últimos anos, a utilização de cama de aviário obteve aumento considerável no Brasil, por representar uma importante fonte alternativa de fertilizante para a agricultura $^{14}$, na qual sua utilização contínua melhora as propriedades químicas, físicas e biológicas do solo ${ }^{15}$. Em alguns casos, em especial, nas pequenas propriedades rurais, pode representar a única fonte de nutrientes aplicada às culturas agrícolas.

O uso de matéria orgânica permite uma racionalização de até um terço na utilização do adubo mineral, porque promove aumento na CTC, evitando perdas por lixiviação, melhorando a agregação; diminuindo a plasticidade e a coesão; diminuindo a oscilação de temperatura e ajudando na liberação dos nutrientes à planta ${ }^{16}$. A demanda de nutrientes, exigidos pela cultura, é diferente da necessidade de adubação e correção, de tal modo que, para se obter rendimentos satisfatórios nas culturas é preciso o uso racional de adubos orgânicos complementados com fertilizantes minerais. Para a utilização da adubação organomineral, são necessários programas de estabelecimento de adubação, visando conseguir que ambos os tipos de fertilizantes contribuam adequadamente nos cálculos das doses indicadas para as culturas ${ }^{17}$.

Com base nessas considerações, o presente trabalho teve por objetivo avaliar o efeito das adubações orgânica e mineral na produtividade e componentes de rendimento da cultura do milho. 


\section{Material e Métodos}

$\mathrm{O}$ experimento foi realizado na fazenda experimental da UEG-Universidade Estadual de Goiás, UnU de Ipameri-GO, na safra 2009/2010, em Latossolo Vermelho-Amarelo Distrófico (Embrapa, 1999), cujas coordenadas geográficas são $17^{\circ} 43^{\prime} 20^{\prime \prime}$ de latitude sul e $48^{\circ} 09^{\prime} 44^{\prime \prime} d e$ longitude oeste e altitude de 800 m. O clima predominante da região é Aw, segundo a classificação de Koppen.

$\mathrm{O}$ delineamento experimental utilizado foi em blocos casualizados, em esquema fatorial $5 \times 5$, com três repetições. $\mathrm{O}$ primeiro fator consistiu em cinco doses de cama de aviário (CA) $0 ; 2,5 ; 5 ; 10$ e $20 \mathrm{Mg} \mathrm{ha}^{-1}$, e o segundo fator, em cinco doses de adubo mineral NPK de formulação 05-25-15 (100, 200, 300, 400 e 500 $\left.\mathrm{kg} \mathrm{ha}^{-1}\right)$. As características químicas do solo da área experimental, antes da aplicação do corretivo, bem como a caracterização do composto orgânico utilizado no experimento encontram-se na Tabela 1. Convém salientar que a área apresentava anteriormente ao período de estudo, pastagem com braquiária (Brachiaria decumbens) em sistema extensivo de manejo, o que explica a baixa fertilidade do solo.

Foi realizada a calagem, visando elevar a saturação de bases do solo a $60 \%$, com aplicação de $1,33 \mathrm{Mg} \mathrm{ha}^{-1}$ de calcário dolomítico (PRNT 85\%), 30 dias antes da semeadura e incorporada a $20 \mathrm{~cm}$ de profundidade no solo por meio de gradagens. O preparo do solo foi realizado da seguinte forma: aração,por meio de duas gradagens, na camada de 0-20 cm com grade intermediária; uma gradagem de nivelamento e destorroamento da superfície do solo com grade leve. A aplicação da CA foi realizada a lanço na área de cada parcela, com a dose correspondente ao tratamento $\left(0 ; 2,5 ; 5 ; 10\right.$ e $\left.20 \mathrm{Mg} \mathrm{ha}^{-1}\right)$ e incorporadas 20 dias antes da semeadura com grade leve. Foram abertos sulcos utilizando um cultivador, para aplicação do fertilizante mineral, a $10 \mathrm{~cm}$ de profundidade. A adubação mineral de semeadura, com uso de formulado NPK (0525-15), consistiu da aplicação das seguintes doses de N, P2O5 e K2O: 100 (22,6-25-15 kg ha $\left.{ }^{-1}\right) ; 200(45,2-50-30 \mathrm{~kg}$ $\left.\mathrm{ha}^{-1}\right) ; 300\left(67,8-75-45 \mathrm{~kg} \mathrm{ha}^{-1}\right) ; 400\left(90,4-100-60 \mathrm{~kg} \mathrm{ha}^{-1}\right) \mathrm{e}$ 500 (113-125-75 $\left.\mathrm{kg} \mathrm{ha}^{-1}\right)$. Para adubação de cobertura, foi utilizado como fonte de $\mathrm{N}$ a uréia, com dose equivalente a $2 / 3$ da dose de N, da dose total do respectivo tratamento, aos 30 dias após emergência da cultura.
Tabela 1. Caracterização química do solo da área experimental e da cama de aviário utilizada.

\begin{tabular}{|c|c|c|c|}
\hline \multicolumn{2}{|c|}{$\begin{array}{l}\text { Caracterização } \\
\text { do Solo }\end{array}$} & \multicolumn{2}{|c|}{$\begin{array}{c}\text { Caracterização } \\
\text { da cama de avário }\end{array}$} \\
\hline Característica & Valor & Característica & Valor \\
\hline $\mathrm{pH}$ em $\mathrm{H} 2 \mathrm{O}$ & 4,3 & $\begin{array}{c}\text { Matéria Orgânica } \\
\qquad(\mathrm{g} \mathrm{kg}-1)\end{array}$ & 74 \\
\hline $\begin{array}{l}\text { Matéria } \\
\text { Orgânica } \\
\left(\mathrm{g} \mathrm{dm}^{-3}\right)\end{array}$ & 24,0 & $\begin{array}{c}\text { Nitrogênio } \\
(\mathrm{g} \text { kg-1) }\end{array}$ & 2,4 \\
\hline $\begin{array}{l}\text { Al Trocável } \\
\left(\mathrm{cmolc} \mathrm{dm}^{-3}\right)\end{array}$ & 0,3 & Relação C/N & 17 \\
\hline $\begin{array}{c}\text { Cálcio } \\
\left(\mathrm{cmolc} \mathrm{dm}^{-3}\right)\end{array}$ & 0,5 & Cálcio $\left(\mathrm{g} \mathrm{kg}^{-1}\right)$ & 4,23 \\
\hline $\begin{array}{c}\text { Magnésio } \\
\left(\mathrm{cmolc} \mathrm{dm}^{-3}\right)\end{array}$ & 0,2 & Magnésio $\left(\mathrm{g} \mathrm{kg}^{-1}\right)$ & 0,83 \\
\hline $\begin{array}{c}\mathrm{H}+\mathrm{Al}(\mathrm{cmolc} \\
\left.\mathrm{dm}^{-3}\right)\end{array}$ & 2,5 & Potássio $\left(\mathrm{g} \mathrm{kg}^{-1}\right)$ & 2,90 \\
\hline $\begin{array}{l}\text { CTC Total } \\
\left(\mathrm{cmolc} \mathrm{dm}^{-3}\right)\end{array}$ & 3,3 & Fósforo $\left(\mathrm{g} \mathrm{kg}^{-1}\right)$ & 5,14 \\
\hline $\begin{array}{l}\text { Potássio } \\
\left(\mathrm{mg} \mathrm{dm}^{-3}\right)\end{array}$ & 47 & Enxofre $\left(\mathrm{g} \mathrm{kg}^{-1}\right)$ & 0,42 \\
\hline $\begin{array}{l}\text { Fósforo } \\
\left(\mathrm{mg} \mathrm{dm}^{-3}\right)\end{array}$ & 5,6 & Sódio $\left(\mathrm{mg} \mathrm{kg}^{-1}\right)$ & 5680 \\
\hline $\begin{array}{c}\text { Saturação por } \\
\text { bases }(\%)\end{array}$ & 25,5 & Ferro $\left(\mathrm{mg} \mathrm{kg}^{-1}\right)$ & 51500 \\
\hline - & - & $\begin{array}{l}\text { Manganês } \\
\left(\mathrm{mg} \mathrm{kg}^{-1}\right)\end{array}$ & 1066 \\
\hline- & - & Zinco $\left(\mathrm{mg} \mathrm{kg}^{-1}\right)$ & 1060 \\
\hline - & _ & Cobre $\left(\mathrm{mg} \mathrm{kg}^{-1}\right)$ & 158 \\
\hline
\end{tabular}

As unidades experimentais foram compostas por quatro fileiras de plantas com 4,0 $\mathrm{m}$ de comprimento, espaçadas $0,9 \mathrm{~m}$ entre si. As sementes do híbrido simples AGN 30A95 foram semeadas manualmente para a obtenção de uma população de 65 mil plantas por hectare, a $5 \mathrm{~cm}$ de profundidade no mesmo sulco da adubação. Posteriormente, para a obtenção dos dados, utilizaram-se as duas fileiras centrais, eliminando-se $0,5 \mathrm{~m}$ nas extremidades, perfazendo uma área útil de $10,8 \mathrm{~m}^{2}$.

O controle de doenças foi realizado de forma preventiva, com duas aplicações de fungicida. A primeira aplicação foi realizada com a cultura em estádio V8, com aplicação do produto à base de mistura de azoxystrobin + ciproconazole, na dose de $0,3 \mathrm{~L} \mathrm{ha}^{-1}$ mais o óleo mineral 
a $0,5 \mathrm{~L} \mathrm{ha}^{-1}$ e, a segunda, com a mesma dose no período inicial da emissão da espiga.

Para o controle da lagarta do cartucho do milho foi utilizado inseticida fisiológico do grupo benzoiluréia, composto com Triflumurom a $480 \mathrm{~g} \mathrm{~L}^{-1}$, sendo aplicado numa dose de $125 \mathrm{ml}$ ha-1, aos 20 dias após emergência e, visando ao controle das plantas daninhas, foi realizada uma capina manual nos estágios iniciais da cultura.

A colheita do milho foi realizada 142 dias após a emergência, sendo avaliados os seguintes parâmetros: a altura total de planta, medindo-se da base ao pendão, a partir de 10 plantas medidas ao acaso; diâmetro do colmo, medindo-se dois diâmetros perpendiculares, na altura da base, a partir de 10 plantas medidas ao acaso; a produtividade de grãos, determinada pela pesagem dos grãos produzidos em cada parcela, corrigindo-se o teor de água para 14\%; número de grãos por fileira, obtido pelo número médio de grãos de quatro fileiras por espiga, utilizando-se 10 espigas representativas por parcela; número de fileiras por espiga, obtido pelo número médio de fileira de 10 espigas representativas por parcela; massa seca de 100 grãos, obtido pela média de quatro amostras da parcela e, massa seca de planta, obtida pela pesagem de duas plantas da parcela, que foram submetidas à secagem, em estufa a $70^{\circ} \mathrm{C}$ até $\mathrm{o}$ seu peso constante.

Os dados foram submetidos à análise de variância e regressão, adotando-se nível de 5\% de probabilidade, para o erro tipo I, utilizando-se o software estatístico SISVAR.

\section{Resultados e Discussão}

$\mathrm{Na}$ Tabela 2, são apresentadas as equações ajustadas, obtidas pela análise de regressão, relacionadas à produtividade e componentes de rendimento da cultura do milho. Constatou-se que houve interações significativas entre cama de aviário e a adubação mineral para todas as variáveis estudadas.Todas as variáveis apresentaram ajustes lineares ou quadráticos e, também, significativos com as doses de cama de aviário aplicadas.

Em relação às doses de NPK, apenas as variáveis produtividade de grãos e massa seca de 100 grãos apresentaram ajustes lineares e quadráticos significativos, entretanto, as variáveis número de grãos por fileira de espiga, altura de plantas e diâmetro do colmo com relação significativa apenas para ajuste linear (Tabela 2).

$\mathrm{Na}$ Tabela 3, são apresentadas as equações de regressão para as variáveis produtividade de grãos, número de grãos por fileira de espiga, massa seca de 100 grãos, altura de plantas e diâmetro do colmo, ajustadas em resposta à adubação NPK nas diferentes doses de cama de aviário. Os ajustes significativos para a produtividade em função das doses de NPK foram obtidos apenas com 0 e 2,5 $\mathrm{Mg} \mathrm{ha}^{-1}$ de cama de aviário, com comportamento linear e, com a dose de $10 \mathrm{Mg} \mathrm{ha}^{-1}$, com ajuste quadrático (Tabela 3). Na ausência de aplicação de cama de aviário, obteve-se um incremento de $800 \mathrm{~kg} \mathrm{ha}^{-1}$ de grãos para cada $100 \mathrm{~kg} \mathrm{ha}^{-1}$ de NPK e produtividade máxima de $7009 \mathrm{~kg} \mathrm{ha}^{-1}$. Quando utilizada 2,5 $\mathrm{Mg} \mathrm{ha}^{-1}$ de cama de

Tabela 2. Resumo do quadro de análise de variância para os ajustes da análise de regressão entre os adubos cama de aviário e NPK sobre as variáveis estudadas. UEG - Ipameri, GO, 2010.

\begin{tabular}{|c|c|c|c|c|c|c|}
\hline \multirow{3}{*}{ Variável - resposta } & \multicolumn{5}{|c|}{ Efeitos } & \multirow{3}{*}{$\mathrm{CV} \%$} \\
\hline & \multicolumn{2}{|c|}{ NPK } & \multicolumn{2}{|c|}{ Cama de aviário } & \multirow{2}{*}{$\begin{array}{c}\text { NPK } x \\
\text { Cama de aviário }\end{array}$} & \\
\hline & $\mathbf{L}$ & $\mathbf{Q}$ & $\mathbf{L}$ & $\mathbf{Q}$ & & \\
\hline Produtividade $\left(\mathrm{kg} \mathrm{ha}^{-1}\right)$ & $* *$ & $* *$ & $* *$ & $* *$ & $* *$ & 12,34 \\
\hline $\mathrm{N}^{o}$ de fileiras de grãos/ espiga & ns & ns & $* *$ & $* *$ & $* *$ & 4,12 \\
\hline $\mathrm{N}^{\circ}$ de grão/ fileira de espiga & $*$ & ns & $* *$ & $* *$ & $* *$ & 8,90 \\
\hline Massa seca de 100 grãos (g) & $* *$ & $*$ & $* *$ & $*$ & $* *$ & 5,73 \\
\hline Matéria seca de plantas $\left(\mathrm{kg} \mathrm{ha}^{-1}\right)$ & ns & ns & $*$ & $*$ & $*$ & 22,90 \\
\hline Altura de plantas (m) & $* *$ & ns & $* *$ & $* *$ & $* *$ & 16,02 \\
\hline Diâmetro do colmo (m) & $*$ & ns & $* *$ & $* *$ & $* *$ & 10,81 \\
\hline
\end{tabular}


Tabela 3. Equações de regressão para as variáveis relacionadas à produtividade de grãos e componentes de rendimento da cultura do milho em respostas à adubação NPK nas diferentes doses de cama de aviário.

\begin{tabular}{|c|c|l|c|}
\hline Variável-resposta & Cama de Aviário (Mg ha-1) & \multicolumn{1}{|c|}{ Equação de regressão } & \multicolumn{1}{|c|}{ R2 } \\
\hline \multirow{3}{*}{ Produtividade de grãos (t ha-1) } & 0 & $\mathrm{y}=7,9948 \mathrm{x}+3012,8$ & $0,71^{* *}$ \\
\cline { 2 - 4 } & 2,5 & $\mathrm{y}=5,5246 \mathrm{x}+5504,3$ & $0,91^{* *}$ \\
\cline { 2 - 4 } & 10 & $\mathrm{y}=-0,0475 \mathrm{x} 2+28,642 \mathrm{x}+6911$ & $0,59^{* *}$ \\
\hline \multirow{2}{*}{ Número de grãos por fileira de espiga } & 0 & $\mathrm{y}=0,0232 \mathrm{x}+15,048$ & $0,98^{* *}$ \\
\cline { 2 - 4 } & 2,5 & $\mathrm{y}=0,0162 \mathrm{x}+21,277$ & $0,91^{* *}$ \\
\hline \multirow{2}{*}{ Massa seca de 100 grãos (g) } & 5 & $\mathrm{y}=-0,00005 \mathrm{x} 2-0,0348 \mathrm{x}+30,759$ & $0,99^{*}$ \\
\cline { 2 - 4 } & 20 & $\mathrm{y}=-0,0069 \mathrm{x}+29,72$ & $0,48^{*}$ \\
\hline Altura de plantas $(\mathrm{m})$ & 0 & $\mathrm{y}=0,0008 \mathrm{x}+1,5339$ & $0,66^{* *}$ \\
\hline Diâmetro do colmo $(\mathrm{cm})$ & 0 & $\mathrm{y}=0,009 \mathrm{x}+12,873$ & $0,54^{*}$ \\
\hline
\end{tabular}

*, **: significativo a $5 \%$ e $1 \%$ pelo teste $\mathrm{F}$, respectivamente.

aviário houve um incremento, aproximando-se de 600 $\mathrm{kg} \mathrm{ha}^{-1}$ de grãos para cada $100 \mathrm{~kg} \mathrm{ha}^{-1}$ de NPK aplicado, porém, com produtividade máxima de $8266 \mathrm{~kg} \mathrm{ha}^{-1}$, superior à obtida na ausência de adubação orgânica. Já na dose de $10 \mathrm{Mg} \mathrm{ha}^{-1}$ de cama de aviário estimou-se uma produtividade máxima de $11.270 \mathrm{~kg} \mathrm{ha}^{-1}$ de grãos, com a aplicação de $304 \mathrm{~kg} \mathrm{ha}^{-1}$ de NPK.

Ajustes lineares significativos do número de grãos por fileira de espiga em função da adubação NPK foram obtidos com as doses de 0 e $2,5 \mathrm{Mg} \mathrm{ha}^{-1}$ de cama de aviário. Sem a aplicação de cama de aviário, obteve-se um incremento de 2,3 grãos por fileira para cada $100 \mathrm{~kg}$ ha- 1 de NPK aplicado, enquanto que, para a dose de 2,5 $\mathrm{Mg} \mathrm{ha}^{-1}$ de cama de aviário, obteve-se um incremento de 1,6 grãos para cada $100 \mathrm{~kg} \mathrm{ha}^{-1}$ de NPK aplicado. Quanto à massa seca de 100 grãos, para a dose de $20 \mathrm{Mg} \mathrm{ha}^{-1}$ de cama de aviário, verificou-se decréscimo de $0,005 \mathrm{~g}$, para cada $100 \mathrm{~kg} \mathrm{ha}^{-1}$ de NPK aplicado. Já para a dose de $5 \mathrm{t} \mathrm{ha}^{-1} \mathrm{de}$ cama de aviário, obteve-se resposta quadrática, com valor mínimo obtido com a dose de $340 \mathrm{~kg} \mathrm{ha}^{-1}$ de NPK.

Os ajustes lineares significativos, na ausência de adubação com cama de aviário, em função da adubação NPK ocorreram para as variáveis altura de plantas e diâmetro do colmo, sendo que, para cada $100 \mathrm{~kg} \mathrm{ha}^{-1}$ de NPK aplicado, houve redução de $8 \mathrm{~cm}$ em altura de planta e $0,9 \mathrm{~cm}$ em diâmetro do colmo.

Pelo desdobramento das doses do adubo mineral, verificaram-se ajustes significativos em todas as doses de
NPK, para a variável produtividade de grãos (Tabela 4). Quando utilizou-se $200 \mathrm{~kg} \mathrm{ha}^{-1}$ de NPK houve resposta linear à aplicação de cama de aviário, obtendo-se um incremento de $281 \mathrm{~kg} \mathrm{ha}^{-1}$ de grãos para cada tonelada de cama de aviário aplicada. Assim como na dose de $500 \mathrm{~kg}$ $\mathrm{ha}^{-1}$ de NPK, em que também se verificou ajuste linear, com incremento de $173 \mathrm{~kg} \mathrm{ha}^{-1}$ de grãos para cada tonelada de cama de aviário aplicada, no entanto, com incremento de $38 \%$ menor que na dose de $200 \mathrm{~kg} \mathrm{ha}^{-1}$ de NPK. Para as doses de 100 e $400 \mathrm{~kg} \mathrm{ha}^{-1}$ de NPK, verificou-se ajuste quadrático, com produtividades máximas de $10.995 \mathrm{~kg} \mathrm{ha}^{-1}$ de grãos na dose de $100 \mathrm{~kg} \mathrm{ha}^{-1}$ de NPK, com a dose de cama de aviário estimada em 16,8 t ha-1, e $10.506 \mathrm{~kg} \mathrm{ha}^{-1} \mathrm{de}$ grãos na dose de $400 \mathrm{~kg} \mathrm{ha}^{-1}$ de NPK, com a dose de cama de aviário estimada em 16,6 Mg ha-1. $\mathrm{Na}^{-}$dose de $300 \mathrm{~kg} \mathrm{ha}^{-1}$ de NPK, que também obteve ajuste quadrático, observou-se produtividade de grãos de $12.180 \mathrm{~kg} \mathrm{ha}^{-1}$ com a dose de 14,8 $\mathrm{Mg} \mathrm{ha}^{-1}$ de cama de aviário, com 10,7 \% de produtividade superior à obtida com $100 \mathrm{~kg} \mathrm{ha}^{-1}$ de NPK.

Quanto ao número de fileiras de grãos, a dose de $100 \mathrm{~kg} \mathrm{ha}^{-1}$ de NPK proporcionou quantidade máxima de 17,88 fileiras, quando associado a uma dose estimada de $14,3 \mathrm{Mg} \mathrm{ha}^{-1}$ de cama de aviário. Já para a dose de $300 \mathrm{~kg}$ ha $^{-1}$ de NPK, a quantidade máxima de fileiras foi de 17,95 unidades, quando associado à dose estimada de $11,79 \mathrm{Mg}$ $\mathrm{ha}^{-1}$ de cama de aviário, enquanto que na dose de $500 \mathrm{~kg}$ $\mathrm{ha}^{-1}$ de NPK, foram obtidas 17,82 fileiras, com uma dose estimada de 13,17 $\mathrm{Mg} \mathrm{ha}^{-1}$ de cama de aviário. 
Tabela 4. Equações de regressão para as variáveis relacionadas à produtividade de grãos e componentes de rendimento da cultura do milho, em respostas à adubação com cama de aviário nas diferentes doses do adubo mineral NPK.

\begin{tabular}{|c|c|c|c|}
\hline Variável - resposta & NPK (kg ha-1) & Equação de regressão & $\mathbf{R 2}$ \\
\hline \multirow{5}{*}{ Produtividade de grãos (t ha-1) } & 100 & $y=-0,027 x 2+0,9119 x+3,3126$ & $0,97 * *$ \\
\hline & 200 & $y=0,2812 x+6,0896$ & $0,91 * *$ \\
\hline & 300 & $y=-0,0327 x 2+0,9705 x+5,0176$ & $0,94 * *$ \\
\hline & 400 & $y=-0,0147 x 2+0,5001 x+6,3392$ & $0,95^{*}$ \\
\hline & 500 & $y=0,173 x+7,37$ & $0,87 * *$ \\
\hline \multirow{4}{*}{ Número de fileiras de grãos por espiga } & 100 & $y=-0,0135 x 2+0,3718 x+15,232$ & $0,72 * *$ \\
\hline & 200 & $y=0,0813 x+16,297$ & $0,44 * *$ \\
\hline & 300 & $\mathrm{y}=-0,0191 \mathrm{x} 2+0,4484 \mathrm{x}+15,322$ & $0,78^{* *}$ \\
\hline & 500 & $y=-0,0178 x 2+0,4487 x+14,874$ & $0,84 * *$ \\
\hline \multirow{5}{*}{ Número de grãos por fileira de espiga } & 100 & $y=-0,0754 x 2+2,3532 x+16,95$ & $0,99 * *$ \\
\hline & 200 & $y=-0,0648 x 2+2,0047 x+19,61$ & $0,95 * *$ \\
\hline & 300 & $y=-0,0532 x 2+1,7819 x+22,87$ & $0,99 * *$ \\
\hline & 400 & $y=0,579 x+25,484$ & $0,97 * *$ \\
\hline & 500 & $y=0,4707 x+27,319$ & $0,87 * *$ \\
\hline \multirow{2}{*}{ Massa seca de 100 grãos (g) } & 200 & $y=0,0237 x 2-0,3907 x+27,763$ & $0,88^{* *}$ \\
\hline & 300 & $y=0,1761 x+25,319$ & $0,73 * *$ \\
\hline \multirow{4}{*}{ Massa seca de planta (g) } & 100 & $y=-26,648 x 2+764,34 x+4006$ & $0,93 * *$ \\
\hline & 200 & $y=176,72 x+5460,7$ & $0,87 * *$ \\
\hline & 300 & $y=227,98 x+4930,6$ & $0,97 * *$ \\
\hline & 400 & $y=123,64 x+5784$ & $0,85^{*}$ \\
\hline \multirow{5}{*}{ Altura de plantas (m) } & 100 & $y=-0,0026 x 2+0,0856 x+1,5749$ & $0,95 * *$ \\
\hline & 200 & $y=0,0208 x+1,8637$ & $0,86^{* *}$ \\
\hline & 300 & $\mathrm{y}=0,0234 \mathrm{x}+1,8531$ & $0,88 * *$ \\
\hline & 400 & $y=0,0155 x+1,9288$ & $0,93 * *$ \\
\hline & 500 & $y=0,0188 x+1,8783$ & $0,78 * *$ \\
\hline \multirow{4}{*}{ Diâmetro do colmo (cm) } & 100 & $y=-0,0394 x 2+1,1804 x+13,6$ & $0,91 * *$ \\
\hline & 200 & $y=0,2497 x+17,021$ & $0,71 * *$ \\
\hline & 300 & $y=0,1987 x+17,177$ & $0,65^{* *}$ \\
\hline & 500 & $y=0,207 x+17,054$ & $0,64 * *$ \\
\hline
\end{tabular}

*,**: significativo a $5 \%$ e $1 \%$ pelo teste $\mathrm{F}$, respectivamente.

Na dose de $300 \mathrm{~kg} \mathrm{ha}^{-1}$ de NPK, a massa seca de 100 grãos apresentou ajuste linear, com incremento de 0,176 g para cada tonelada de cama de aviário aplicada, na dose de $200 \mathrm{~kg} \mathrm{ha}^{-1}$ de NPK, sendo o valor mínimo obtido, pelo ajustamento quadrático, foi de $25,78 \mathrm{~g}$, com dose estimada de $8,24 \mathrm{Mg} \mathrm{ha}^{-1}$ de cama de aviário, com tendência de aumento, a partir desta dose.

Para número de grãos por fileira de espiga, as doses de 100,200 e $300 \mathrm{~kg} \mathrm{ha}^{-1}$ de NPK apresentaram resposta quadrática, sendo que para a dose de $100 \mathrm{~kg} \mathrm{ha}^{-1}$ foi obtido 35,39 grãos por fileira, quando associado com uma dose estimada de 15,69 $\mathrm{t} \mathrm{ha}^{-1}$ de cama de aviário. Para com a dose de $200 \mathrm{~kg} \mathrm{ha}^{-1}$, obtiveram-se 35,27 grãos por fileira de espiga, quando associado a uma dose estimada de $15,65 \mathrm{Mg} \mathrm{ha}^{-1}$ de cama de aviário. Já com a dose de 300 $\mathrm{kg} \mathrm{ha}^{-1}$ de NPK, foram obtidos 41,38 grãos por fileira de 
espiga, quando associados com uma dose de $18,8 \mathrm{t} \mathrm{ha}^{-1}$ de cama de aviário, podendo ser uma justificativa para a obtenção de maiores produtividades deste tratamento.

Vários autores verificaram a superioridade da adubação orgânica, em relação à adubação mineral. Nas culturas da alface e rúcula, efeitos significativos na altura e diâmetro de plantas e no número de folhas por planta, em que os maiores valores foram obtidos com o cultivo orgânico associado à adubação mineral ${ }^{18}$. Em estudos com a cultura da erva mate, maior rendimento de massa verde foi obtido com cama de aviário, superando até a adubação exclusivamente mineral ${ }^{19}$.

Em estudos com pimentão, verificou-se que a aplicação de composto orgânico, na ausência da adubação mineral, com teores de $\mathrm{N}$ entre 40,1 e 44,3 $\mathrm{g} \mathrm{kg}^{-1}$, evidenciando que somente com a utilização da adubação orgânica, as plantas apresentaram-se bem nutridas em $\mathrm{N}^{20}$. Possivelmente, a maior produtividade proporcionada pelo uso de cama de aviário é devido à adequada concentração de nutrientes para a cultura em sua composição, melhor capacidade de aumentar a troca de cátions e elevação do acúmulo de umidade do solo ${ }^{21}$.

A interação entre cama de aviário e adubo mineral provavelmente possibilitou efeito de sinergismo, em que a utilização da cama de aviário, potencializando a adubação mineral, promoveu adequado balanceamento da adubação à cultura. Esse comportamento deve-se não apenas pelo fornecimento de nutrientes, como na adubação mineral, mas também, devido aos seus efeitos benéficos como aumento da atividade microbiana, melhoria da aeração e infiltração de água no solo 22 .

A utilização de fontes orgânicas de nutrientes nas culturas agrícolas é uma alternativa viável técnica e economicamente ${ }^{23}$. Contudo, sua eficiência pode ser maximizada, quando associada à adubação mineral, especialmente para aumentar a quantidade de nitrogênio disponível desde o início do ciclo da cultura, o qual é particularmente importante quando do uso da cama de aviário, que por conter maior quantidade de nutrientes, é uma alternativa melhor do que outras fontes orgânicas.

\section{Conclusão}

Houve interações significativas entre a adubação com NPK e a cama de aviário para todos os parâmetros avaliados; enquanto a adubação orgânica promoveu incremento na produtividade e nos componentes de rendimento do milho. De maneira geral, os melhores resultados foram obtidos na dose de 15 toneladas por hectare de cama de aviário associada com $300 \mathrm{~kg} \mathrm{ha}^{-1}$ de adubo mineral NPK.

\section{Referências}

1. Lopes, M. 2007. Disponível em: http://www.embrapa.br/ imprensa/artigos/2007/artigo.2007-02-14.4893566264/\# acesso em 24/07/2013.

2. Conab- Campanha Nacional de Abastecimento. Disponível em: http://www.conab.gov.br/olalacms/uploads/arquivos/7e 05515f822 2082610088f5a2376c6af..pdf

3. Cruz, J. C.; Pereira Filho, I. A.; Alvarenga, R. C.; Gontijo Neto, M. M.; Viana, j. H. M.; Oliveira, M. F.; Santana, D.P. Circular Técnico, 87: 1-12, 2006.

4. Bull, 1. T. Piracicaba: Potafós, 1993.147-196.

5. Marchesini, A.; Allievi, 1.; Comotti, E.;Ferrari, A. Plant and Soil, Dordrecht, v. 106, p. 253-261, 1988.

6. Smith, S. R.; Hadley, P. Journal of Horticultural Science, Ashford, v. 63, n. 4 , p. $615-620,1988$.

7. Vidigal, S. M.; Ribeiro, A.C.; Casali, V. W. D.; Fontes, 1. E. F. Resposta da Alface (Lactuca Sativa 1.) Ao Efeito Residual da Adubação Orgânica: i. Ensaio de Campo. Revista Ceres, Viçosa, v. 42 , n. 239 , p. $80-88,1995$.

8. Martins, S.R. Revista Cientifica Rural, Bagé, v.4, n.2, p.175-187, 1999.

9. Kage, H. In: Fundação Cargill (ed.). Adubação Verde no Brasil. Campinas: Cargill, 1984. P. 124-128.

10. Gomes, J.A. Dissertação (Mestrado em Fitotecnia) - Universidade Federal de Viçosa, Viçosa, 1995.

11. Cantarella, H.; Van Raij, b. In: Simposio Sobre Adubação Nitrogenada no Brasil, 1986, Ilhéus. Anais... Ilhéus: SBSC, 1986. P. 243-273.

12. Cantarella, H. In: Bull, 1.t.; Cantarella, h. (ed.). Piracicaba: Potafos, 1993. P. 147-196.

13. Malavolta, E. São Paulo: Agronômica Ceres, 1981.

14. Moreira, C.R.; Siqueira, M.M.; Tavares, M.H.F. In: Reunião Brasileira de Manejo do Solo e da Água, 13., Ilhéus, BA, 2000. Anais... Ilhéus, Bahia: [s.n.], 2000

15. Gliessman, S. R. Porto Alegre, RS: UFRGS, 2000. 642 p.

16. Bissani, C.A.; Gianello, c.; Tedesco, M.J.; Camargo, F.A.O. (EDS Porto Alegre, Gênesis, 2004. 328p.

17. Ciancio, N.H.R. Dissertação (Mestrado) - Universidade Federal de Santa Maria, Centro de Ciências Rurais, Programa de PósGraduação em Ciência do Solo, 2010. 85 p. 
18. Oliveira, E.Q; Souza, R.J; Cruz, M.C.M; Marques, V.B; França, A.C. Horticultura Brasileira 2010. 28: 36-40.

19. Pandolfo, C.M; Floss, P.A; Crose, D.M; Dittrich, r.c. 2003. Ciência Floresta, Santa Maria 13: 37-45.

20. Sediyama, M.A.N; Vidigal, S.M; Santos, M.R; Salgado, L.t. Horticultura Brasileira 2009. 27: 294-299.

21. Kiehl, E.J. Piracicaba: Degaspari. 2008.680p.

22. Paulus, G; Muller, A.M; Barcellos, L.A.R. 2000. Porto Alegre: Emater-rs. 86p.

23. Fioreze, C.; Ceretta, C.A. Ciência Rural, Santa Maria, RS v.36, n.6, p.1788-1793, 2006.

\section{André L. S. Pereira', Adilson Pelá*, Gláucia M. Pelá, Rogério N. Gonçalves², Rodrigo T. Mendes ${ }^{3}$ \& Odilon P. M. Júnior ${ }^{4}$}

\footnotetext{
${ }^{1}$ Bayer CropScience

${ }^{3}$ Solar Agrícola, Ipameri-GO

${ }^{4}$ Universidade Federal de Goiás, UFG, Brasil.

*e-mail: adilson.pela@ueg.br
}

${ }^{2}$ Universidade Estadual de Goiás, UEG, UnU Ipameri, Rodovia GO 330, Km 241, Anel Viário, CEP 75780-000, Ipameri, GO, Brasil. 